\title{
Structural and biophysical characteristics of human skin in maintaining proper epidermal barrier function
}

\author{
Magdalena Boer ${ }^{1}$, Ewa Duchnik ${ }^{1}$, Romuald Maleszkaํ, Mariola Marchlewicz² \\ ${ }^{1}$ Department of Skin and Venereal Diseases, Pomeranian Medical University, Szczecin, Poland \\ ${ }^{2}$ Department of Aesthetic Dermatology, Pomeranian Medical University, Szczecin, Poland
}

Adv Dermatol Allergol 2016; XXXIII (1): 1-5

DOI: 10.5114/pdia.2015.48037

\begin{abstract}
The complex structure of human skin and its physicochemical properties turn it into an efficient outermost defence line against exogenous factors, and help maintain homeostasis of the human body. This role is played by the epidermal barrier with its major part - stratum corneum. The condition of the epidermal barrier depends on individual and environmental factors. The most important biophysical parameters characterizing the status of this barrier are the skin $\mathrm{pH}$, epidermal hydration, transepidermal water loss and sebum excretion. The knowledge of biophysical skin processes may be useful for the implementation of prophylactic actions whose aim is to restore the barrier function.
\end{abstract}

Key words: epidermal barrier, sebum, skin hydration, transepidermal water loss, skin pH.

Skin is a barrier between the human body and the external environment. It protects the body against exogenous chemical and physical factors, takes part in the metabolic processes, plays a resorptive and thermoregulatory function, being the first line of defence against pathogenic microorganisms, and it partakes in immunological processes [1].

The complex structure of human skin and its physicochemical characteristics turn it into an effective outermost defence line against exogenous factors, and help maintain homeostasis of the human body. This role is played by the epidermal barrier, in which the corneal layer of epidermis has a particularly important function to perform [1-3]. It consists of 15-20 layers of fully cornified keratinocytes corneocytes. In the bottom part of the cornified layer, the cells closely adjoin each other, while in the top part they are arranged loosely and undergo scaling. Construction of the corneal layer resembles a wall in which corneocytes stand for bricks, and a fat-abundant intercellular matrix is the cement $[4,5]$. The interior of the corneal layer cells is filled with cytokeratin filaments bonded with filaggrin. These cells are surrounded by a stiff, cornified encasement built mostly of the loricrin protein, forming a part of the so-called protein-lipid envelope [2, 3, 6]. The envelope is connected with the extracellular liquid crystal matrix and constitutes the border between the hydrophilic surface of the cells and the lipophilic non-polar fatty acids of the matrix surrounding corneocytes [7].
The thickness of the outer layer of the epidermis, the size of corneocytes, and the composition of superficial lipids impact the regenerative properties of the skin, which contributes to the various courses of dermatological diseases, and the process of healing alike. Anatomical areas with thick epidermis are more resistant to external factors [8]. On the other hand, the areas with a relatively thin cornified layer, such as the face, are characterized by high susceptibility to damaging factors, but also by the ability to re-establish the barrier function very fast. It is connected with a high proliferative activity, thus quick regeneration of the epidermis, intensive vascularity, good hydration, and presence of many sweat glands [9].

The condition of the epidermal barrier depends on its physical properties, such as the amount of sebum produced, epidermis hydration, transepidermal loss of water, and the $\mathrm{pH}$ gradient between the surface of the skin and the inside of the body [1]. Many individual and environmental factors impact the modification of the abovementioned processes, including the age, sex, race, anatomical area of the skin, intensity of perspiration, skin temperature and ambient temperature, humidity of the air, season of the year, daily rhythm, hormonal balance, and many others [10-14].

The surface of the cornified layer is covered by a lipid film, which plays a very important role in the functioning of the epidermal barrier. It comes from two sources: se-

Address for correspondence: Magdalena Boer MD, PhD, Department of Skin and Venereal Diseases, Pomeranian Medical University, 2 Siedlecka St, 72-010 Police, Poland, phone/fax: +48 9142539 24, e-mail: m.boer@onet.eu

Received: 21.05.2014, accepted: 17.07.2014. 
bum secreted by the sebaceous glands, constituting the greatest part of the lipid mantle, and the epidermal lipids, forming a part of the cornified layer of the epidermis $[5,15,16]$. The thickness of the lipid mantle amounts to $0.5 \mu \mathrm{m}$ to $5 \mu \mathrm{m}$, depending on the number of sebaceous glands in a given area [5].

Lipids of the intercellular matrix of the corneal layer of epidermis develop in the process of conversion of their precursors provided by multilamellar Odland corpuscles of the granular layer [17]. The polar lipids are converted into non-polar ones, hydrolysis of glycolipids generates ceramides, whereas phospholipids are metabolized into free fatty acids. These processes result in the creation of a structure consisting of tightly packed lamellas, positioned parallel to the surface of the epidermal cells [2, 4-6]. Intercellular lipids are mainly sphingolipids, or ceramides (45-50\%), as well as cholesterol (20-25\%), saturated free fatty acids (10-15\%), and small amounts of non-polar lipids [17 18]. In the human skin we may differentiate nine sub-classes of ceramides marked 1 to 9 , depending on the chemical structure of the main group. Fractions of the length of the carbon chain C24 to C26 are most often found among ceramides. The ceramide which plays the principal role in the epidermis is the linoleic acid [7]. On the other hand, among free fatty acids, those with the chain length of C22 and C24 appear to dominate. Around $2-5 \%$ of the matrix constituents is cholesterol sulphate, which is responsible for the inhibition of proteolytic enzymes, digesting desmosome links between the epidermal cells $[2,7,17,18]$.

Sebum is a sticky liquid and is a mixture of non-polar lipids. It consists of triglycerides ( 16\%), free fatty acids ( $33 \%)$, wax esters $(\sim 26 \%)$, squalene $(\sim 12 \%)$, cholesterol esters $(\sim 3 \%)$, and cholesterol $(\sim 1.5 \%)[19,20]$. The dominant fatty acids are essential fatty acids of the length of carbon chain C16 and C18, whereby the dominant acid is the oleic acid [18, 21-23]. Among the saturated fatty acids, the palmitic acid is the most common. The composition of sebum is relatively constant, and its changes may entail some skin diseases. The biggest changes in the composition of sebum are observed in adolescents, during intensified hydrolysis of triglycerides into free fatty acids. Production of sebum is a very dynamic process, conditioned by individual characteristics and environmental factors. The observed production of sebum is bigger in men than in women $[5,19,24]$. Production of sebum depends on the density, location and activity of sebaceous glands [25]. In such areas as the scalp, the T zone of the face, the sternum or the interscapular areas, their density amounts to 900 per square centimetre of the skin, but in other places less than 100 sebaceous glands per square centimetre are observed $[19,26]$.

Sebum takes part in the creation of the 3-dimensional structure of epidermal lipids, which helps maintain its integrity [20, 23, 27]. It forms a protective layer against the multiplication of pathogenic microorganisms, having both proinflammatory and anti-inflammatory properties [28]. The amount of produced sebum has an influence on the increase of colonisation with numerous microorganisms which derive nutritious substances from the sebum, e.g. Propionibacterium acnes or Malassezia yeasts [21]. Sebum forms a type of insulation against excessive humidity and variations of ambient temperature [20]. Moreover, it helps maintain the water binding capacity of the epidermis $[8,28]$. Proper production of sebum correlates with a high level of moistening of the cornified layer [11]. Thanks to its physicochemical characteristics, it impacts the selective permeation of compounds applied onto the skin [5]. Moreover, it has antioxidant properties and shields the skin from UBV radiation, which is connected to the dysfunction of the sebaceous platelet-activating acetylhydrolase II [4].

Lipids of the cornified layer play a very important role in the regulation of the absorption of various compounds from the surface of the skin [5]. There are two ways of absorption: through the epidermis and through the skin appendages. The principal way is selective absorption through the epidermis. The lamellar, bi-layer structure of opposite electric charge of extracellular lipids facilitates dissolving lipophilic substances. Their hydrophobic properties prevent excessive loss of water and dissolution of hydrophilic substances [29]. The absorption of substances from the surface of the skin depends to a great degree on the size of corneocytes of the cornified layer, and is proportional to the capacity of intercellular space, and inversely proportional to the size of the cells [30]. Non-polar compounds of a molecular weight below 500 Da easily permeate through the epidermis [31]. The absorption of substances through skin appendages (sweat glands, sebaceous glands, hair follicles) takes place only to a modest extent. It is referred to as the fast permeation path due to lesser selectivity and possibility of absorbing bigger molecules. For that reason the areas with many sweat glands, such as the face or the upper part of the torso, are more exposed to the absorption of potentially proinflammatory substances, often the cause behind skin eruptions [8].

The surface of healthy skin can be characterised by acidic $\mathrm{pH}$, oscillating between 4.0 and 6.0. The $\mathrm{pH}$ of human internal organs is close to neutral - between 7.35 and 7.46 , being differentiated in various areas of the skin. The highest $\mathrm{pH}$ values are observed in the most hydrated areas, such as skin folds and articular fossae [32]. The maintenance of acidic $\mathrm{pH}$ depends on the creation of free fatty acids, mainly lactic acid and amino acids, hydrogen and ammonium compounds, as well as on the composition of sebum lipids and the proteins of the corneal layer of the epidermis [33]. These constituents determine the creation of $\mathrm{pH}$ gradient connected with the significant difference between its value on the skin surface and within the living layers of the epidermis, where it reaches the value of approx. 7.0 [34]. This way, the so-called buffer volume of epidermis is maintained [32]. 
A significant role in the creation of the acid coat is played by the correct activity of lipolytic enzymes, taking part in the metabolism of the intracellular lipids of the corneal layer. Acidic pH in the lower layers of epidermis is maintained by sodium/proton exchange proteins - NHE. They remove $\mathrm{H}^{+}$ions from the cells, and draw $\mathrm{Na}^{+}$ions, at the same time protecting the intracellular environment against acidification [34]. The $\mathrm{pH}$ value may be modified by the level of skin hydration, atmospheric conditions, the intensity of sweat secretion and physical activity. Additionally, it depends on genetic factors, co-morbidities and the medications or cosmetics used $[33,35]$. Sex most probably does not affect the differences in the $\mathrm{pH}$ value $[5,10,33]$, although there are some reports suggesting that there is such correlation [34-36]. Also age does not modify this value, yet among new-borns and people above 80 years of age, higher $\mathrm{pH}$ values are noted [33, 34, 37].

Acid $\mathrm{pH}$ of the skin surface and the difference between the $\mathrm{pH}$ of the skin surface and the $\mathrm{pH}$ of the deeper layers of the corneal layer of epidermis control the physiological flora and potentially infectious one. The growth pace and the colonisation density of bacteria and fungi increase with the increase of $\mathrm{pH}$. On the other hand, the presence of saprophytic microorganisms has a positive influence on the maintenance of the acidity of skin surface, among others by means of triglyceride breakdown to free fatty acids [34].

The correct $\mathrm{pH}$ also takes part in the maintenance of correct hydration of the epidermis. Its increase activates cathepsins, breaking down filaggrin, and decreasing in this way the creation of the natural moisturizing factor (NMF) [34]. Increased pH values correspond also with an increase in transepidermal water loss (TEWL), one of the most significant indicators of the epidermal barrier function $[11,33]$. Moreover, the skin $\mathrm{pH}$ plays one of the most important roles in the correct organisation of the matrix lipids, by regulating their surface structure and stability [18]. Intracellular lipids are sensitive to $\mathrm{pH}$ fluctuations which might modify hydrolytic reactions, causing the change of their composition and spatial structure [2, 17].

The integrity of the epidermal barrier protects the skin against the excessive loss of water and protects the maintenance of correct hydration of epidermis. Water is accumulated thanks to the corneal layer of epidermis and the amount of water in this layer is defined as the skin hydration [38]. The correct level of moisture is affected by such factors as the amount of water supplied from the bottom layers of epidermis, dermis and sebaceous glands, and also the amount of water lost through evaporation and the ability of the corneal layer to accumulate water. Water retention in this layer is also affected by the presence of lipids of the extracellular matrix and the protein coat of the cells [3].

The corneal layer maintains the water gradient between the skin surface and bottom layers of the epidermis. Keratinocyte hydration decreases with their passage from the basal layer to the epidermis surface [5]. Water constitutes approximately $15-20 \%$ of the total mass of the corneal layer and accumulates mostly inside corneocytes, whilst in the living layers of epidermis, water constitutes as much $70 \%$ of its mass [17]. The most superficial - the top part of the corneal layer is the least hydrated and under large influence of external factors on water contents. The thickness of the cornified layer is $30 \mu \mathrm{m}$. After liberal moistening, it rises even to $40 \mu \mathrm{m}$ [2]. The deepest part of epidermis contains more water and thus the impact of external environment is insignificant. The middle area, in turn, is the zone with the highest possibilities of regulating water accumulation. It is characterised with a high concentration of NMF, which is located inside corneocytes [3]. The natural moisturising factor is responsible for the maintenance of the correct hydration of epidermis and skin plasticity. It constitutes 10-30\% of the dry mass of corneal layer and consists mostly of free amino acids and their metabolites, such as urocanic acid (UCA) and pyrrolidone carboxylic acid which are the products of filaggrin proteolysis. Other constituents of the corneal layer with hygroscopic properties are lactates, urea, proteins, saccharides, organic acids and numerous electrolytes secreted through sweat glands as well as glycerol delivered by sebaceous glands $[3,8,17]$.

The lipids of the intracellular space of the corneal layer of epidermis counteract the excessive loss of water from epidermis, mostly thanks to their anatomical and biochemical structure, which makes them play the role of a barrier constituent $[17,29]$. They are parallel plates, packed closely adherent to each other, and protect against water evaporation from inside the corneal layer of epidermis. A special role is played by the presence of ceramides which increase water retention in the corneal layer [2, 39, 40]. A decrease in the contents of ceramides, cholesterol and free fatty acids of the intracellular matrix decrease skin moisture [3]. In the process of hydration of living layers of the epidermis, an important role is played by aquaporin-3. It is a constituent of water channels of cell membranes, facilitating the transport of water, urea and glycerol into the epidermis cells [21]. The correct content of water within dermis is maintained thanks to hyaluronic acid, owing to its hydrophilic properties. Some smaller quantities of this acid can be also found in the intracellular matrix of the corneal layer [17].

The epidermis hydration values vary depending on the anatomical area. The highest values can be found on the facial skin, articular fossae, lower values - on the forearms whilst the lowest - on the shins $[8,10,38$, 41]. This depends mostly on epidermis thickness and the location of sebaceous and sweat glands [3, 8]. The moisture level changes also depending on the ambient moisture and temperature. These parameters affect water retention and the degree of its evaporation from the corneal layer, having some influence on the change of hydration gradient between the epidermis and the envi- 
ronment [41, 42]. Moreover, the moisture value may also be affected by the type of consumed foods. One of the studies has shown that epidermal hydration is decreased as a result of the diet rich in saturated or monounsaturated fatty acids [43].

The loss of water from the skin is a result of the secretion of sweating and transepidermal passive diffusion. Water loss through epidermis is described by TEWL value and affects the level of epidermis moisture [44, 45]. Transepidermal water loss is a parameter reflecting the integrity of epidermis water layer and is a very sensitive indicator of the damage of the epidermis barrier [1, 8, 14, $18,31,39,46]$. Transepidermal water loss is a gradient of the vapour pressure measured in two points lying perpendicular to the skin surface inside an open chamber and is an intermediate value of water transmission from corneal layer. In stable ambient conditions, TEWL oscillates around $4-10 \mathrm{~g} / \mathrm{h} / \mathrm{m}^{2}$, depending on the skin area, but it may increase even up to a 30 times higher value when epidermis is damaged [1]. The TEWL value changes even under the influence of such factors as skin temperature, blood flow through skin vessels, the pace of epidermis regeneration, the thickness of corneal layer, the lipid contents in corneal layer, the number and activity of sweat glands on a given skin area, ambient temperature and humidity and many others $[1,8,37,41]$. This parameter depends on the correct structure of the junctions between the cells of the corneal and granular layers, which are the place of the passage between a low and high concentration of water. These connections regulate the transmission of water and other substances dissolved in it to living layers of the epidermis [17]. The highest TEWL values are found on the skin of palms, soles, face, genitals and the areas of joints; whereas the lowest - on the calves $[41,46]$. Transepidermal water loss values most probably do not depend on sex [10, 31, 46], although some studies point to higher values of this parameter among men [47]. Its changeability depending on age is also controversial $[37,46]$. Most probably lower TEWL values occur among people above 60 years of age [31]. This parameter influences also the regulation of epidermis exfoliation and enzymatic functions accompanying keratinisation. The more intensive water loss, the more intensive the keratinisation process is, which has its clinical manifestation in excessive exfoliation and erythema [17, 48].

An indicator of healthy skin is the correct function of epidermal barrier protecting against external factors and against pathogenic microorganisms. The loss of structural or functional integrity of this barrier facilitates the occurrence of skin lesions accompanying many dermatological diseases. The knowledge of biophysical processes within the skin may be useful for the implementation of prophylactic actions whose aim is to restore the barrier function and to protect against the development of pathological lesions and can be also helpful in initiating effective treatment.

\section{Acknowledgments}

The name of the department to which the work should be attributed: Department of Skin and Venereal Diseases, Pomeranian Medical University, Szczecin.

\section{Conflict of interest}

The authors declare no conflict of interest.

\section{References}

1. Hongbo Z, Maibach HI. Dermatotoxicology. $6^{\text {th }}$ edition. CRC Press LCC, USA 2004; 938-55.

2. Bouwstra JA, Honeywell-Nguyen PL, Gooris GS, et al. Structure of the skin barrier and its modulation by vesicular formulations. Prog Lipid Res 2003; 42: 1-36.

3. Rudikoff D. The effect of dryness on the skin. Clin Dermatol 1998; 16: 99-107.

4. Maghraby GM, Barry BW, Williams AC. Liposomes and skin: from drug delivery to model membranes. Eur J Pharm Sci 2008; 34: 203-22.

5. Pailler-Mattei C, Nicoli S, Pirot F, et al. A new approach to describe the skin surface physical properities in vivo. Colloid Surf B Biointerfaces 2009; 68: 200-6.

6. Stawczyk-Macieja M, Szczerkowska-Dobosz A, Rębała K, Purzycka-Bohdan D. Genetic background of skin barrier dysfunction in the pathogenesis of psoriasis vulgaris. Adv Dermatol Allergol 2015; 32: 123-6.

7. Bouwstra JA, Ponec $M$. The skin barrier in healthy and diseased state. Biochim Biophys Acta 2006; 1758: 2080-95.

8. Tagami H. Location-related differences in structure and function of the stratum corneum with special emphasis on those of the facial skin. Inter J Cosmet Sci 2008; 30: 413-34.

9. Fluhr JW, Dickel H, Kuss O, et al. Impact of anatomical location on barrier recovery, surface $\mathrm{pH}$ and stratum corneum hydration after acute barrier disruption. Br I Dermatol 2002; 146: $770-6$

10. Darlenski R, Fluhr JW. Influence of skin type, race, sex, and anatomic location on epidermal barrier function. Clin Dermatol 2012; 30: 269-73.

11. Darlenski R, Sassning S, Tsankov N, et al. Non-invasive in vivo methods for investigation of the skin barrier physical properties. Eur J Pharm Biopharm 2009; 72: 295-303.

12. Marques M, Pei Y, Southall MD. Identification of plateletactivating factor acetylhydrolase II in human skin. J Invest Dermatol 2002; 119: 913-9.

13. Muizzuddin N, Hellemans L, Van Overloop L, et al. Structural and functional differences in barrier properties of African American, Caucasian and East Asian skin. J Dermatol Sci 2010; 59: 123-8.

14. Ramos-e-Silva M, da Silva Carneiro SC. Elderly skin and its rejuvenation - products and procedures for the aging skin. J Cosmet Dermatol 2007; 6: 40-50.

15. Sobjanek M, Sokołowska-Wojdyło M, Barańska-Rybak W, et al. Rola czynników hormonalnych w etiopatogenezie i terapii trądziku pospolitego. Adv Dermatol Allergol 2006; 23: 266-72.

16. Youn SW, Na JI, Choi SY, et al. Regional and seasonal variations in facial sebum secretions: a proposal for the definition of combination skin type. Skin Res Technol 2005; 11: 189-95.

17. Verdier-Sevrain S, Bonte F. Skin hydration: a revive on its molecular mechanisms. J Cosmet Dermatol 2007; 6: 75-82 
18. Plasencia I, Norlen L, Bagotolli LA. Direct visualization of lipid domains in human skin stratum corneum's lipid membranes: effect of pH and temperature. Biophys J 2007; 93: 3142-55.

19. Giacomoni PU, Mammone T, Teri M. Gender-linked differences in human skin. J Dermatol Sci 2009; 55: 144-9.

20. Zouboulis CC. Acne and sebaceous gland function. Clin Dermatol 2004; 22: 360-6.

21. Nordstrom KM, Labows JN, McGinley KJ, et al. Characterization of wax esters, triglicerydes, and free fatty acids of follicular casts. J Invest Dermatol 1986; 86: 700-5.

22. Ro In B, Dawson TL. The role of sebaceous gland activity and scalp microfloral metabolism in the etiology of seborrheic dermatitis and dandruff. I Investig Dermatol Symp Proc 2005; 10: 194-7.

23. Thormar $\mathrm{H}$, Hilmarsson $\mathrm{H}$. The role of microbidical lipids in host defense against pathogens and their potential as therapeutic agents. Chem Phys Lipids 2007; 150: 1-11.

24. Kim MK, Patel RA, Shinn AH. Evaluation of gender difference in skin type and pH. J Dermatol Sci 2006; 41: 153-6.

25. Rode B, Ivens U, Serup J. Degreasing method for the seborrheic areas with respect to regaining sebum excretion rate to casual level. Skin Res Technol 2000; 6: 92-7.

26. Downie MMT, Guy R, Kealey T. Advances In sebaceous gland research: potential new approaches to acne management. Inter J Cosm Sci 2004; 26: 291-311.

27. Winiarska A, Majewski S. Rola sebocytów w fizjologii i w stanach patologicznych skóry. Przegl Dermatol 2007; 94: 233-40.

28. Youn SW, Na JI, Kim SJ, et al. Evaluation of facial skin type by serum secetion: discrepancies between subjective descriptions and serum secretion. Skin Res Technol 2002; 8: 168-72.

29. Gliński W. Rola bariery skórnej w naturalnej obronie przed zakażeniami. Mikol Lek 2002; 9: 13-6.

30. Levin J, Maibach H. The correlation between transepidermal water loss and percutaneous absorption: an overview. J Contr Rel 2005; 103: 291-9.

31. Placek W, Kałużna L, Górnicki A, et al. Wpływ wybranych emolientów na przeznaskórkową utratę wody (TEWL). Dermatol Estet 2004; 6: 95-9.

32. Chikakane K, Takahashi H. Measurement of skin pH and its significance in cutaneous diseases. Clin Dermatol 1995; 13: 299-306.

33. Yosipovitch G, Maibach HI. pH powierzchni skóry: kwaśny płaszcz ochronny. Cosmet Toiletr 1996; 111: 101.

34. Lambers H, Piessens S, Bloem A, et al. Natural skin surface $\mathrm{pH}$ is on average below 5 , which is beneficial for its resident flora. Int J Cosmet Sci 2006; 28: 359-70.

35. Ehlers C, Ivens UI, Molle ML, et al. Females have lower surface $\mathrm{pH}$ than men. Skin Res Technol 2001; 7: 90-4.

36. Segger D, Assmus U, Brock M, et al. Multicenter study on measurement of the natural $\mathrm{pH}$ of the skin surface. Inter J Cosmet Sci 2008; 30: 75.

37. Marrakchi S, Maibach HI. Biophysical parameters of skin: map of human face, regional, and age-related differences. Contact Dermatitis 2007; 57: 28-34.

38. O'goshi K, Serup J. Inter-instrumental variation of skin capacitance measured with the Corneometer ${ }^{\circledR}$. Skin Res Technol 2005; 11: 107-9.

39. Huang HC, Chang TM. Ceramide 1 and ceramide 3 act synergistically on skin hydration and the transepidermal water loss of sodium lauryl sulfate-irritated skin. Int I Dermatol 2008; 47: 812-9.

40. Patel SD, Noble WC. Analyses of skin surface lipid in patients with microbially associated skin disease. Clin Exp Dermatol 1993; 18: 405-9.
41. Black D, Del Pozo A, Lagarde JM, et al. Seasonal variability in the biophysical properties of stratum corneum from different anatomical sides. Skin Res Technol 2000; 6: 70-6.

42. Cravello B, Ferri A. Relationship between skin properties and environmental parameters. Skin Res Technol 2008; 14: 180-6.

43. Boelsma E, van de Vijver L, Goldbohm A, et al. Human skin conditions and its associations with nutrient concentrations in serum and diet. Am J Clin Nutr 2003; 77: 348-55.

44. Holm E, Wulf HC, Thomassen L, et al. Instrumental assessment of atopic eczema: validation of transepidermal water loss, stratum corneum hydration, erythema, scaling, and oedema. J Am Acad Dermetol 2006; 55: 772-80.

45. Mavon A, Redoules D, Humbert P, et al. Changes in sebum levels and skin surface free energy components following skin surface washing. Colloids Surf B Biointerfaces 1998; 10: 243-50.

46. Szepietowski J, Kozera M, Strzelecka E, et al. Przeznaskórkowa utrata wody (TEWL) na przedramieniu: zależność od miejsca, płci i wieku. Dermatol Klin Zabieg 2000; 2: 67-70.

47. Firooz A, Sadr B, Babakoohi S, et al. Variation of biophysical parameters of the skin with age, gender, and body region. Sci World J 2012; 2012: 386936

48. Dawnson T, Gemmer C, DeAngelis Y, et al. Dandruff and seborrheic dermatitis likely result from scalp barrier breach and irritation induced by Malassezia metabolites, particularly free fatty acids. J Am Acad Dermatol 2005; 53: P49. 